\title{
A CULTURA MATERIAL COMO DISCIPLINA FILOLÓGICA: DO MANUSCRITO AO TEXTO ELETRÔNICO
}

Marcelo Módolo*

(iD) http://orcid.org/0000-0001-5808-9368

Maria de Fátima Nunes Madeira**

(iD) http://orcid.org/0000-0001-6141-0714

Como citar este artigo: MÓDOLO, M.; MADEIRA, M. de F. N. A cultura material como disciplina filológica: do manuscrito ao texto eletrônico. Todas as Letras - Revista de Lingua e Literatura, São Paulo, v. 23, n. 1, p. 1-16, jan./abr. 2021. DOI 10.5935/ 1980-6914/eLETDO2114349

Submissão: março de 2021. Aceite: março de 2021.

Resumo: Para refletir sobre a cultura material como disciplina da Filologia, apresentaremos o manuscrito datado de 1755, uma carta-régia, comentando a sua trajetória, desde a sua criação, como documento administrativo, até a sua edição nos meios eletrônicos. Para tanto, recorremos à perspectiva da transdisciplinaridade da Filologia, que se entrelaça com ciências como a Arquivologia, a Codicologia, a Paleografia, a Diplomática, a Bibliografia material e as Humanidades digitais com o objetivo de aproximar o texto escrito e seus questionamentos do leitor contemporâneo.

Palavras-chave: Cultura material. Manuscrito. Filologia. Transdisciplinaridade. Edição eletrônica. 


\begin{abstract}
Desse modo, a atividade no campo no patrimônio cultural é complexa, delicada e trabalhosa. Exige postura crítica rigorosa. Exige capacidade de ir além de suas próprias preferências pessoais. Mas por isso também é tão fascinante e gratificante, pois estamos tratando, não de coisas, mas daquela matéria-prima - os significados, os valores, a consciência, as aspirações e desejos - que fazem de nós, precisamente, seres humanos. Ulpiano T. Bezerra de Meneses (2009)
\end{abstract}

\title{
CONSIDERAÇÕES INICIAIS
}

O conceito de cultura material como "aquele segmento do meio físico que é socialmente apropriado pelo homem" (MENESES, 1983, p. 112), quando associado à documentação - manuscrita ou impressa -, ensina que a leitura dos documentos "não deve buscar apenas o que foi escrito, mas também como foi escrito, por que foi escrito e como aquele texto circulou e foi guardado" (LARA, 2008, p. 22). Só assim esses documentos podem se transformar em fontes de pesquisas históricas.

Também a Filologia se apropria das propriedades da cultura material da escrita para cumprir a sua função de

[...] interrogar os objectos escritos sobre a sua proveniência e a sua existência, antes de os declarar aptos a serem lidos pelos outros, os literatos, os linguistas, e outros que, distraidos pelas suas especialidades, tendem demasiadas vezes a confiar em que a palavra escrita é sempre a palavra do seu autor (CASTRO, 1984 apud MARQUILHAS, 2010, p. 360).

As metodologias interdisciplinares de ciências como a Codicologia, a Paleografia, a Diplomática e a Bibliografia material é que tornam possivel a tarefa da análise material dos documentos gráficos no âmbito da Filologia. Essas investigações propiciam a edição fidedigna de textos escritos, datados das mais diversas épocas, para serem publicados e utilizados como fontes de pesquisa confiáveis.

As marcas deixadas no suporte de um manuscrito, de um códice ou de um livro impresso descrevem não somente aspectos sobre a sua autenticidade, como também sobre a história da trajetória desses objetos, ou seja, a sua biografia ${ }^{1}$. Os estudos sobre o papel, a tinta, o instrumento de escrita, a própria escrita, a estrutura formal de um documento diplomático e as técnicas do livro manuscrito ou impresso são informações com as quais o filólogo estabelece um diálogo para tentar compreender "como suas formas e aparência foram concebidas e que usos foram dados ao objeto ao longo de sua história” (ALMADA, 2014, p. 138).

Dessa forma, consideramos que o texto, como patrimônio cultural escrito, razão de ser da Filologia, carrega os requisitos necessários para ser apresentado na perspectiva de curadoria textual, metodologia pela qual o filólogo favorece o encontro entre o texto e o leitor, distanciados pela ação do tempo, a partir de explicações sobre os aspectos de sua materialidade.

Sob esse enfoque - do texto escrito como objeto que revela principalmente suas formas de elaboração, marcas e vestígios de uso em seus lugares de pouso -, apresentaremos a materialidade do texto da carta-régia de 1755, que compõe, com outros três documentos, o códice AL 014 do Instituto de Estudos Brasilei-

1 Termo cunhado por Meneses (2003, p. 11 apud ALMADA, 2014, p. 137), referindo-se a fontes visuais: "é necessário retraçar a biografia, a carreira, a trajetória das imagens". 
ros da Universidade de São Paulo (IEB/USP). Debruçadas sobre esse documento, que cumpriu o seu ciclo de vida desde a sua criação, numa sede administrativa colonial, até chegar ao arquivo permanente e depois ser transformado em fonte de pesquisas, as disciplinas filológicas interagem para estudar as questões propostas pela cultura material.

\section{O ARguivo, O ARguIVIsta E O Códice}

O caminho para uma pesquisa científica na área de humanidades tem grandes chances de começar num arquivo, por isso, quanto mais o pesquisador souber sobre as peculiaridades dos arquivos, maiores as chances de se encontrar o objeto buscado para a pesquisa. Além disso, o pesquisador pode contar com serviços editoriais, de difusão cultural e de assistência educativa dos arquivos para aprimorar os seus estudos, pois, conforme Bellotto (2006, p. 178):

Só um arquivo munido de um guia geral de fundos, inventários e catálogos parciais, e cuja equipe de arquivistas possa preparar em tempo razoável catálogos seletivos e edições de textos, quando pertinentes, estará cumprindo sua função junto à comunidade científica e ao meio social de que depende e a que serve.

Arquivos públicos (municipais e estaduais) e particulares, especializados em documentações governamentais, pessoais, econômicas, religiosas, notariais, de movimentos e entidades públicas, entre outras, são opções disponíveis para consultas presenciais em grande parte das cidades brasileiras. Se a consulta se expandir para a internet, as opções alcançam cidades do mundo inteiro.

O IEB/USP, que abriga o códice que vamos utilizar neste estudo, é um centro multidisciplinar de pesquisas e documentação sobre a história e as culturas do Brasil, onde acervo e pesquisa são indissociáveis. A coleção Alberto Lamego, por exemplo, compreende livros raros, vários tipos de impressos e cerca de 4.600 manuscritos, muitos deles relacionados à administração portuguesa na Colônia.

Os dados do arquivo do IEB, cujo acervo está disponivel para pesquisadores do mundo inteiro, podem ser consultados na opção "catálogo on-line", no site da instituição ${ }^{2}$. Já o conteúdo dos documentos somente pode ser consultado presencialmente, mediante agendamento por e-mail. Nessa visita, é possivel olhar, tocar e fotografar os documentos, sempre com os devidos cuidados (uso de máscara e luvas, por exemplo).

A localização do documento no códice AL-014 da coleção Alberto Lamego, no IEB, referencia o percurso da carta-régia a partir de seu último local de pouso. O tratamento da materialidade do documento pelo arquivista, ainda no âmbito do arquivo, onde o manuscrito foi classificado e catalogado, obedecendo aos parâmetros estabelecidos pela teoria arquivística, ressalta a função do arquivista tanto na preservação desse patrimônio cultural quanto na garantia da possibilidade de consulta:

A integridade e a integralização de acervos documentais, o resgate e o processamento técnico dos documentos, seguidos da divulgação das informações neles contidas, são a essência da sua tarefa profissional no âmbito dos arquivos permanentes (BELLOTTO, 2006, p. 263).

\footnotetext{
2 Disponivel em: http://www.ieb.usp.br
} 
DOSSIÊ

Os dados apresentados na catalogação do documento AL 014-002, imprescindiveis para os estudos da materialidade do manuscrito - a espécie documental, a entidade produtora, o destinatário, a função, a datação tópica e cronológica, a forma ${ }^{3}$ e a quantidade de páginas -, garantem maior segurança às análises do pesquisador:

Carta régia de D. José I, rei de Portugal, ao juiz e oficiais da Câmara de Sabará para a contribuição de um subsídio voluntário da capitania de Minas Gerais para a reconstrução de Lisboa, deixando ao arbitrio das autoridades a forma de arrecadação. Belém, 16 de dezembro de 1755. 2p. (Cópia: 29 de julho de 1777) (Catálogo online do Arquivo do IEB/USP ${ }^{4}$, item 362, p. 37).

O IEB conta também com um catálogo impresso, editado por ocasião das comemorações dos 40 anos do instituto e do centenário de Sérgio Buarque de Holanda, no qual se encontram valiosas informações sobre a coleção Alberto Lamego, que desde 2002 faz parte do projeto Reencontro (descrição e microfilmagem de documentos de interesse português no Brasil), uma contrapartida do projeto Resgate ${ }^{5}$ (descrição e microfilmagem de documentos de interesse brasileiro em Portugal).

\section{O códice, A Codicologia e o manuscrito}

Segue a imagem do códice, uma encadernação costurada, medindo $360 \mathrm{~mm}$ de altura e $230 \mathrm{~mm}$ de largura, encapada com tecido de juta, na cor rosada, apresentando pequenas avarias causadas por insetos.

Figura 1 - Capa do códice AL 014

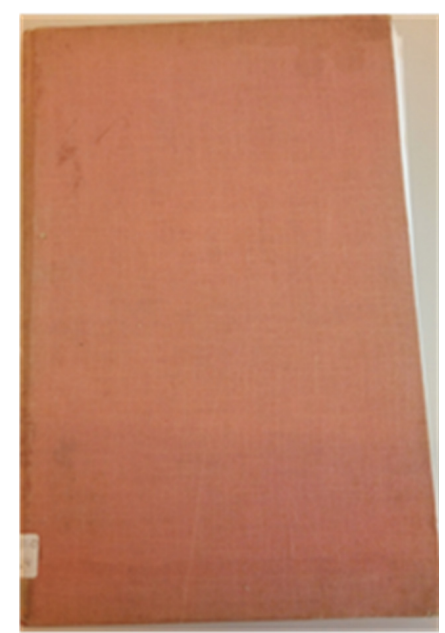

Fonte: Reprodução fotográfica da imagem realizada pelos autores.

Configuração do documento segundo o estágio de transmissão ou gradação de ingenuidade documental (BELLOTTO, 2002, p. 105).

Disponivel em: http://www.ieb.usp.br

Cooperação arquivística internacional de pesquisa remota. Para conhecer o projeto em detalhes, ler: $O$ projeto resgate de documentação histórica Barão do Rio Branco: acesso às fontes da história do Brasil existentes no exterior. Disponível em: https:/l periodicos.ufpe.br/revistas/revistaclio/article/view/24293. Acesso em: 28 fev. 2021. 
A descrição da materialidade do códice, além de complementar as informações da imagem, principalmente para os leitores que não tiveram a oportunidade do contato físico com esse objeto, traz informações significativas para compreender o processo de transmissão desses textos à contemporaneidade.

Nesse caso, por exemplo, a própria encadernação gerou algumas questões. Por exemplo, poder-se-ia imaginar que o códice AL 014 fora confeccionado à época da criação dos documentos que abriga, em 1777, conforme a lógica da área notarial ou das chancelarias e secretarias. Entretanto, no catálogo impresso do IEB, lemos que Alberto Lamego mandava - ele mesmo - encadernar os documentos de sua coleção, o que os arquivistas classificam como códice inautêntico. A partir dessa informação, pode-se conjecturar sobre outros aspectos materiais, como o modo de confecção, a comparação entre essa encadernação e a de um códice autêntico, a idade dessa encadernação e a sua eficácia na função de preservar os documentos encadernados que, depois de chegarem de volta ao Brasil, passaram pela casa de Airizes, a moradia de Lamego, em Campos de Goytacazes, onde foram expostos a consultas, até serem entregues à guarda da Faculdade de Filosofia, Ciências e Letras e, por fim, serem custodiados pelo IEB, com toda a coleção de Lamego.

Apesar de ser um códice inautêntico, os documentos juntados nesse códice têm uma certa lógica. Podemos inclusive inferir que eles permaneceram sempre juntos, como um conjunto avulso de documentos. O primeiro documento é uma representação, assinada no dia 4 de agosto de 1777 , pelos oficiais da Câmara da Vila Real de Sabará e encaminhada à rainha D. Maria I, informando que a capitania de Minas Gerais não estava mais em condições de continuar enviando o subsídio voluntário, dada a decadência em que se encontrava. Os demais documentos são cópias que foram anexadas a essa representação como comprovantes dos argumentos utilizados no texto. Entre esses documentos copiados em 1777, consta a carta-régia, originalmente de 16/12/1755, na qual o rei D. José I ordenava a instituição de um imposto para ajudar na reconstrução de Lisboa.

A cópia dessa carta foi lavrada no mesmo tipo de suporte dos demais documentos do códice, produzidos no mesmo dia. É possível notar que a preocupação com a qualidade dos materiais utilizados era proporcional à preocupação com a durabilidade dos documentos: papel de trapos (algodão, linho ou cânhamo), de boa gramatura, na cor originalmente bege; presença de vergaturas (de $1 \mathrm{em} 1 \mathrm{~mm}$ ) e pontusais (oito por fólio, a cada $26 \mathrm{~mm}$ ); presença de marca d'água, evidenciando um brasão com árvore no cimo, enfeitada com rolos de papiro, e as letras HCW \& Zoonen, indicando as iniciais do nome do fabricante holandês do papel; pena de ganso; e tinta ferro-gálica. Vale lembrar que a identificação desse tipo de marcas, viabilizada pelo contato físico entre o pesquisador e o documento, só é possível se o arquivo disponibilizar a consulta presencial ao manuscrito.

Até mesmo os carimbos e anotações tardias a lápis, que poderiam ser mal recebidos por supostamente corromperem a originalidade do manuscrito, são informações úteis para confirmar lugares de pouso do códice, evidenciando o trajeto realizado pelo documento.

Todas essas marcas deixadas no suporte material contribuem para a validação das datas tópica e cronológica constantes nos documentos, com as quais 
é possível investigar a autenticidade desses, mas também dizem muito sobre as ações políticas na escolha dos testemunhos escritos da história das sociedades que foram selecionados para serem preservados (PETRUCCI, 1999 apud ALMADA, 2014).

\section{O manuscrito, a Paleografia e a leitura}

Não faz muito tempo que os documentos escritos passaram a ser reconhecidos, pela historiografia atual, como suportes materiais que carregam relações culturais: "A documentação escrita deve também integrar o escopo dos estudos sobre a cultura material, fazendo uso de metodologias próprias, que unam também os métodos e interesses da história da cultura escrita" (ALMADA, 2014, p. 141).

No entanto, os estudos sobre a escrita e as informações contidas nos textos sempre foram valorizados. Para Acioli (1994, p. 5), "Das ciências auxiliares da História, a Paleografia é a mais importante porque ela se dedica ao estudo da escrita sobre material brando, principal fonte de informação do historiador".

Coulmas (1999) indica, como uma das funções da escrita que a distinguem da fala, a reificação, em que a elocução se destaca do emissor e ganha presença física estável no suporte material.

Partindo dessa materialidade da escrita no suporte, os estudos paleográficos, cujas metodologias de leitura, de análise e de identificação com a história social da escrita resultam na sua decifração, na constituição sócio-histórica dos sistemas de escrita e na sua interpretação, também possibilitam a avaliação da autenticidade de um documento.

Para a realização dessa tarefa, Petrucci (2002, p. 6-7) propõe as seguintes perguntas:

1. O que está escrito?

2. Quando foi escrito?

3. Onde foi escrito?

4. Como foi escrito?

5. Quem escreveu?

6. Por que escreveu?

As respostas a essas perguntas brotam do próprio manuscrito. Como a escrita humanística cursiva, nesse caso, apresenta pouca diferença entre um modelo caligráfico ${ }^{6}$ e a execução da escrita, não oferecendo grandes dificuldades de leitura, reconhece-se de imediato um texto em lingua portuguesa. Percebe-se a necessidade de explicações acerca da alografia ${ }^{7}$ dos grafemas $<$ s $>$ e $<$ h $>$, da grafia de algumas palavras em comparação à ortografia atual e das abreviaturas.

\footnotetext{
6 A variação na execução individual dos elementos gráficos, condicionada pela atenção e pela habilidade do escriba, em determinado ambiente social, pode aproximar esses elementos do modelo canônico de uma escrita ou distanciá-los dele, quanto maior for a cursividade (TOLEDO NETO, 2018, p. 297).

7 Diferentes tipos de grafia de uma letra.
} 
Nota-se a presença dos reclames, repetição de palavras ao final de um fólio e no início do fólio seguinte, recurso que facilita a recuperação da leitura, já que não se usava ainda a numeração de páginas. Mas nada disso impossibilita a leitura do manuscrito. Contando rapidamente como o terremoto havia arruinado os palácios, os templos e as alfândegas, o texto da carta apela para a lealdade dos vassalos do rei para decidirem os melhores meios de se conseguirem recursos para a necessária e urgente reconstrução de Lisboa. A leitura também permite a identificação das datas tópica (local) e cronológica (data) do manuscrito, respondendo assim à segunda e terceira perguntas da Paleografia. A autenticidade dessas datas é investigada a partir da análise dos aspectos da escrita e das práticas gráficas comuns no século XVIII, estudo que responde à quarta pergunta, ou seja, descreve a maneira como o texto foi escrito: módulo pequeno e homogêneo das letras, ductus cursivo, leveza do traçado, ângulo inclinado à direita, ornamentos nas iniciais maiúsculas, junção de palavras, respeito às pautas e linhas imaginárias, paragrafação, sinais de pontuação e abreviaturas. Por sua vez, essas informações demonstram a habilidade do escrivão e começam a responder à quinta pergunta. O escrivão da Câmara da Vila Real de Sabará que copiou o documento tinha prática e muito provavelmente sabia ler e escrever, numa época em que a alfabetização era um privilégio no Brasil. E o conjunto dessas práticas gráficas, habituais em documentos produzidos nas sedes administrativas setecentistas, tanto em Portugal quanto no Brasil, demonstram, segundo Magalhães (2014, p. 7), que "a escrita foi meio de articulação e comunicação entre os dois lados do Atlântico”, representando informação, ordem, hierarquia e mobilização.

Para responder à última pergunta, o motivo pelo qual o texto foi escrito, é necessário contextualizar o documento principal do códice, a representação. No ano de 1777, tendo morrido o rei D. José I, a rainha D. Maria I assumiu o trono. Vendo aproximar-se o ano de 1778 e a probabilidade de ser mais uma vez prorrogado o imposto do subsídio voluntário, os oficiais da Câmara da Vila Real de Sabará escreveram uma representação para informar que as condições precárias da Vila e da capitania inviabilizariam esse pagamento. Para comprovar os argumentos, os documentos foram copiados e anexados, inclusive a carta-régia. Em seu estudo sobre a relação entre escrita e municipalismo no Brasil Colônia, ao longo do século XVIII, Magalhães (2014, p. 309) constata que "os municípios foram instâncias de ordenamento, poder e decisão, por estatuto próprio e por delegação régia".

Para que os leitores deste estudo façam a experiência da leitura de um manuscrito, com todas as suas particularidades setecentistas, apresentamos a seguir o fac-simile da imagem do documento. Propositadamente, a transcrição será apresentada mais adiante. 
DOSSIÊ

Figura 2 - Fólio 1 recto

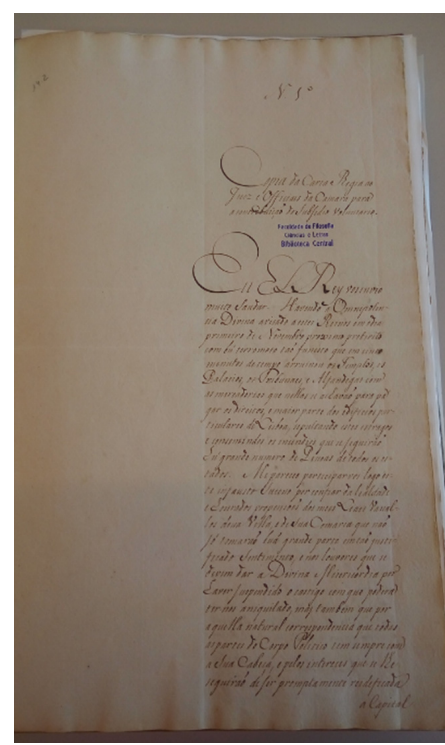

Fonte: Reprodução fotográfica das imagens realizada pelos autores.

Figura 3 - Fólio 1 verso

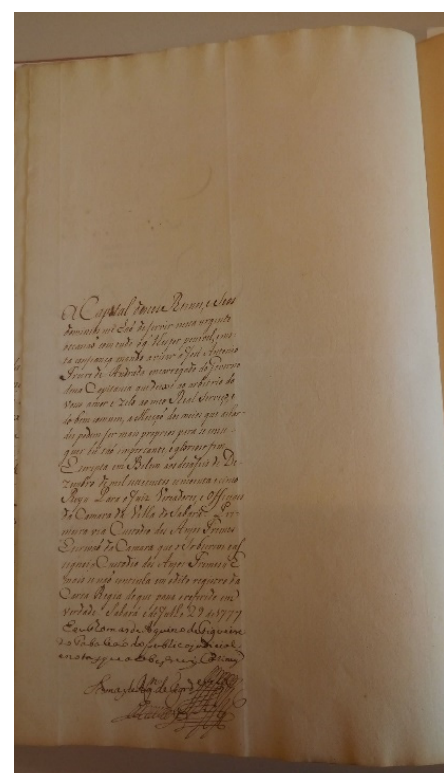

Fonte: Reprodução fotográfica das imagens realizada pelos autores.

\section{A leitura, a Diplomática e A transmissão do manuscrito}

Somente após a fixação confiável do texto do manuscrito em novo suporte, o que inclusive lhe garante a preservação e maior longevidade, pode-se então 
iniciar o estudo de como esse documento foi produzido, em que espécie documental foi lavrado e como se estrutura internamente, ou seja, quais são suas propriedades diplomáticas.

A carta-régia, anexo $\mathrm{N}^{\circ}$ do códice, documento diplomático, dispositivo normativo, descendente, contém uma ordem real, dirigida a uma determinada autoridade ou pessoa e iniciada pelo nome dela. Nesse caso, a carta-régia é dirigida ao juiz e oficiais da Câmara da Vila Real de Sabará. Sua estrutura segue o modelo diplomático dessa espécie documental: 1. protocolo inicial: Eu, El Rei, vos envio muito saudar; 2. texto: a carta narra a destruição causada pelo terremoto ocorrido no dia $1^{\circ}$ de novembro de 1755 e pede a contribuição de um subsídio voluntário para a reconstrução de Lisboa, deixando ao arbítrio das autoridades a forma de arrecadação; e 3. protocolo final: datas tópica e cronológica e subscrição - Rei. Como se trata de uma cópia, o documento apresenta os nomes e assinaturas com sinais públicos do escrivão e do tabelião.

A análise diplomática é realizada para se compreender o documento do ponto de vista de sua autenticidade e da fidedignidade do conteúdo no momento de sua produção. As fórmulas estabelecidas para cada espécie documental devem ser seguidas rigorosamente no texto, para dar fé e força de prova aos documentos.

Além de identificar a estrutura das espécies documentais, a Diplomática também verifica a sua forma, isto é, a configuração que o documento assume conforme o estágio de transmissão ou gradação de ingenuidade documental. O catálogo do IEB informa que a carta-régia deste estudo se configura como uma cópia. Classificada pela Diplomática como cópia autorizada, trata-se de um traslado, pois foi lavrada por escrivão autorizado e validada por tabelião, que a autenticou, recebendo assim a mesma fé notarial e força jurídica do original.

O certo é que, além dessa cópia, que foi adquirida pelo colecionador Alberto Lamego em Portugal, temos notícia de, no mínimo, mais uma, localizada no Arquivo Histórico Ultramarino e consultada remotamente. Mas como a rotina administrativa sempre se valeu da prática de se manter uma das cópias (ou original) dos documentos no arquivo corrente, por segurança, podemos conjecturar a possibilidade de localização de mais uma cópia desse conjunto de manuscritos no Arquivo Público Mineiro, para onde a documentação da Câmara da Vila Real de Sabará foi transferida, após o seu uso funcional. Esse questionamento só pode ser levantado se o pesquisador conhecer o ciclo vital dos documentos administrativos, que compreende três idades: a primeira, dos arquivos correntes; a segunda, dos arquivos intermediários; e a terceira, dos arquivos permanentes.

As propriedades filológicas da cópia autenticada da carta-régia demonstram a sua tramitação desde a sua origem, numa sede administrativa do Brasil colonial, até se transformar em fonte científica e cultural, no arquivo permanente. São 244 anos de história comprovados não só pelo conteúdo do texto escrito, mas principalmente pelas marcas deixadas no suporte material.

\section{A transmissão, A EDIÇÃo E UM NOVO SUPORTE PARA O MANUSCRITO}

Dessa forma, agregando conceitos, conhecimentos específicos e métodos de trabalhos das disciplinas filológicas que lidam com o documento escrito, como a Arquivística, a Codicologia, a Paleografia e a Diplomática, foi sendo composta a história da existência da carta-régia, cuja edição em novo suporte passa a garantir sua longevidade, inclusive em meio digital. 
A edição do texto, chamada semidiplomática, foi realizada de acordo com normas $^{8}$ conservadoras, que mantêm as características originais do texto, ao mesmo tempo que assinalam intervenções que tornam o texto mais compreensivel a um público mais abrangente de leitores. A partir do estabelecimento do texto no processador de texto Word, da Microsoft, o leitor pode conferir as dúvidas despontadas pela consulta ao manuscrito feita diretamente na imagem fac-similar:

\begin{tabular}{lcrrr}
$\|1 r\|^{9}$ & \multicolumn{4}{c}{ Número $1^{\circ}$} \\
Copia & da Carta & Regia & ao \\
Juiz & Officiaes da & Camara & para \\
a contribuiçaõ do Subsidio voluntario &
\end{tabular}

10

$5 \mathrm{Eu}$ El Rey vos envio muito saudar. Havendo a Omnipoten= cia Divina avisado a estes Reinos em o dia primeiro de Novembro proximo pretérito com hũ terromoto tã̃ funesto que em cinco

10 minutos de tempo arruinou os Templos, os Palacios, os Tribunaes, e Alfandegas com as mercadorias que nellas se achavaĩ para pa gar os direitos, e maior parte dos edificios par= ticulares de Lisboa, sepultando estes estragos

$15 e$ consomindos $^{11}$ os incendios que se seguiraõ hũ grande numero de Pessoas de todos os es= tados. Me pareceo participar vos logo es= te infausto Sucesso por confiar da lealdade e honrados propensoẽs dos meos Leais Vassal=

20 los dessa Villa, e de sua Comarca que naõ só tomarã̃ huã grande parte em tã̃ justi= ficado Sentimento, e nos louvores que se devem dar a Divina Misericordia por haver suspendido o castigo com que podera 25 ter-nos aniquilado, mas tambem que por aquella natural correspondencia que todas as partes do Corpo Politico tem sempre com a Sua Cabeça, e pelos intereces que se the seguiraõ de ser promptamente reideficada

\footnotetext{
8 1. Na edição, as linhas são enumeradas de cinco em cinco, a partir da quinta. 2. A posição do acento respeita o mais fielmente possível a sua posição no modelo. 3. Os alógrafos contextuais de caracteres são uniformizados segundo o alfabeto atual. 4 . As abreviaturas são desenvolvidas, marcando-se - em itálico - as letras omitidas, respeitando a grafia do manuscrito. 5. Erros evidentes no modelo são indicados em nota de rodapé, ao lado da lição correta, da seguinte forma: espaço ] espaço. 6. Os sinais públicos, diferentemente das assinaturas e rubricas simples, são sublinhados e indicados entre colchetes.

9 Presença de anotação tardia: 14.2, a lápis, na margem esquerda superior, na altura da linha onde consta "N $1^{\circ " .}$

10 Presença de carimbo retangular: Faculdade de Filosofia Ciências e Letras Biblioteca Central.

11 consomindos ] consomindo
} 
$\|1 v\| a$ Capital destes Reinos, e Seos dominios me hã̃ de servir nesta urgente occasiaõ com tudo o que lhes for possivel, e nes= ta confiança mando avisar a Jose Antonio

35 Freire de Andrada encarregado do Governo dessa Capitania que deixe ao arbitrio do vosso amor e zelo ao meo Real Serviço, $e$ do bem comum, a elleiçaõ dos meios que achar= des podem ser mais proprios para se conse=

40 guir hũ taõ importante, e glorioso fim.

Escripta em Belem aos desaseis de= zembro de mil settecentos cincoenta e cinco Rey // Para o Juiz Vereadores, e Officiaes da Camara da Villa do Sabará. Pri= 45 meira via Custodio dos Anjos Fremes Escrivaõ da Camara que o Sobscrevi $e$ as signei// Custodio dos Anjos Fremes// E mais se naõ continha em o dito registro da Carta Regia de que passa o referido em

50 Verdade. Sabará e de Julho 29 de 1777

E eu Thomas de Aquino de Figueire do Tabaliaõ do publico judicial $e$ notas que o Sobescrevi e asiney [Thomas de Aquino de Figueiredo] [Custódio dos Anjos Fremes]

Tendo em vista que a transcrição é um processo de produção de um novo testemunho do texto, a carta-régia continuará assim sendo transmitida a gerações futuras, impressa em novo suporte. Daí a importância de a transcrição ser o máximo possivel fiel ao original. Nesse momento, o labor filológico se entrelaça com as Humanidades digitais, na tarefa de edição, preservação e acesso aos documentos. Aliás, atualmente, uma variedade de opções para edições na modalidade eletrônica "amplia os horizontes técnicos do trabalho filológico, por libertar as técnicas de representação editorial das limitações materiais colocadas anteriormente pela tecnologia do impresso" (SOUSA, 2013, p. 127 apud FACHIN; OLIVEIRA, 2019, p. 252).

\section{A Bibliografia MATERIAL E A HistóRIA do LIVRo}

Enquanto a Codicologia estuda a técnica do códice, ou seja, do livro manuscrito, a Bibliografia material lida com as técnicas do livro impresso.

$\mathrm{Na}$ passagem do códice para o livro impresso, manteve-se a forma de paginação, inclusive com os reclames; alguns caracteres que imitavam o manuscrito, como o <S> longo; o acabamento pela mão do iluminador; e a composição de folhas dobradas, reunidas em cadernos e encadernadas.

Por isso, apesar de o livro manuscrito se constituir de um processo distinto do impresso, os aspectos analisados nos estudos das duas técnicas são praticamente os mesmos, ou seja, é necessário descrever, além da identificação, datação 
e lugar de origem, os elementos da materialidade desses objetos. Esses elementos são basicamente os mesmos analisados nos manuscritos avulsos, tais como: tipo de suporte (papiro, pergaminho, papel), tipo de tinta, instrumento de escrita, dimensão da mancha na página, número de colunas e linhas, número de fólios. Acrescenta-se, para a análise do códice e do livro impresso, as características da encadernação, nos dois casos, como a composição, o tipo de encadernação e, obviamente, as particularidades de cada um, como a tipografia, no impresso.

Sugerimos, para complementar os estudos sobre os aspectos fundamentais da materialidade relacionada à história dos manuscritos, dos códices e dos livros impressos: Arns (2007), Bouza (2002), Cambraia (2005), Chartier (1994), Dias (2007) e Favoreto (2016).

\section{O TEXTO ESCRITO E ELETRÔNICO}

Como vimos até aqui, a carta-régia manuscrita e assinada em 1755, a qual relatava o terremoto de Lisboa e ordenava a instituição de um imposto para a reconstrução da "capital dos reinos", caminhou no tempo e no espaço, chegando ao século XXI como mais um exemplar de fonte de pesquisas científicas, recebendo uma edição eletrônica. Esse mesmo caminho foi ou será seguido pelos incontáveis manuscritos - avulsos ou encadernados em códices - que ainda serão editados e por todos os livros impressos, pois a digitalização dos textos escritos já é uma realidade, tanto que a Bibliografia material se junta às disciplinas que estudam o texto escrito para refletir sobre os

[...] abismos entre a descrição da materialidade (de acordo com as heranças dos séculos XVIII, XIX e XX) e a descrição estruturada a partir de um sistema de representação descritiva automatizado (século $\mathrm{XX}$ ) - conforme pode ser observado nas análises de descrições produzidas nesses períodos (ARAÚJO, 2019).

Apesar da recepção positiva da ideia de um acervo de textos eletrônicos numa biblioteca universal, que pode ser acessada por todos, em qualquer tempo e lugar, e as perspectivas que a digitalização já colocou em prática para as edições filológicas, as preocupações ainda são muitas. Chartier (1994, p. 185) lança como reflexão para os estudiosos, os cientistas, os escritores, os editores e os leitores - a seguinte pergunta, que aponta para a comparação entre a materialidade e a imaterialidade dos textos:

Como, na longa história do livro e da relação ao escrito, situar a revolução anunciada, mas, na verdade, já iniciada, que se passa do livro (ou do objeto escrito), tal qual o conhecemos, com seus cadernos, folhetos, páginas, para o texto eletrônico e a leitura num monitor?

Não à toa, as páginas que abrimos no Word se assemelham a uma folha de papel em branco. A história do livro, que passa pelo manuscrito, pelo rolo e pelo códice acompanha a história humana há mais de 20 séculos. É difícil desvincular as duas histórias. Chartier (1994, p. 194) completa essa ideia afirmando que "a significação ou, antes, as significações, histórica e socialmente diferenciadas de um texto, seja qual for, não podem ser separadas das modalidades materiais por meio de que o texto é oferecido aos leitores". E Almada (2014, p. 145) complementa, argumentando que "os objetos recebem, cristalizam e reorganizam 
sentidos provenientes das mais diversas origens, em trocas culturais que são fundamentais para a composição e compreensão da realidade vivida".

Por isso, a Crítica textual, a Codicologia, a Paleografia, a Diplomática, a Bibliografia material e as Humanidades digitais estão mutuamente comprometidas com as questões que envolvem a digitalização dos textos escritos. A Arquivologia já enfrentou essa problemática especialmente com a microfilmagem, digitalização e disponibilização de documentação entre países que já mantiveram relação de dependência, como Brasil e Portugal. O projeto de cooperação arquivística internacional, intitulado projeto Resgate, que atua dentro dos parâmetros da pesquisa remota, proporciona aos pesquisadores, a distância, a leitura na íntegra de documentos que antigamente só podiam ser consultados de modo presencial, o que dificultava muito os estudos, dados os variados empecilhos de deslocamento entre Brasil e Portugal. Realizado por especialistas de diversas áreas, o sistema de microfilmagem e digitalização dessa massa de documentos permitiu a preservação da memória histórica brasileira, a padronização nas formas de busca segundo padrões internacionais e a rapidez de acesso. E, fato a se destacar, os documentos físicos foram todos preservados.

A preocupação sobre "a devida catalogação e a identificação dos objetos materiais presentes em um acervo, para torná-los acessiveis para pesquisa e consulta de modo mais eficaz possivel" (FACHIN; OLIVEIRA, 2019, p. 251) é unânime entre os cientistas que estudam o texto escrito. Todos concordam que, já que a digitalização é um caminho sem volta, então os textos digitais precisam ser muito bem catalogados, armazenados e hospedados, já que muitas vezes os sites ficam fora do ar, "devorados por aquele que seria o papirógrafo de nossa época, 'o erro 404', ou a temivel mensagem que surge no navegador: Page not found" (FACHIN; OLIVEIRA, 2019, p. 258).

Além disso, é preciso rever as noções de direitos autorais e de biblioteconomia para a catalogação, classificação e descrição bibliográfica dessa documentação incorpórea.

Do outro lado, temos os manuscritos, os códices, os livros impressos, que precisam continuar sendo coletados, protegidos, recenseados e estar sempre acessiveis na biblioteca do futuro, "lugar onde poderão ser mantidos o conhecimento e a compreensão da cultura escrita nas formas que foram e ainda são, majoritariamente, aquelas hoje conhecidas" (CHARTIER, 1994, p. 195).

\section{CONSIDERAÇÕES FINAIS}

O manuscrito de 1777, encadernado em códice inautêntico, foi utilizado como exemplo de texto escrito cujo trajeto demonstrou a importância da análise da cultura material para os estudos filológicos. Cumprindo o seu ciclo de vida, que teve origem primeiro em Portugal, quando o rei D. José I assinou essa cartarégia, e depois, quando copiada e autenticada, na Câmara da Vila Real de Sabará, esse manuscrito foi transferido para o Arquivo permanente, considerado por Charles Braibant (apud BELLOTTO, 2006, p. 23) um "celeiro da história". Os arquivos e os arquivistas desempenham papel fundamental na coleta, identificação, descrição, resumo e indexação nos catálogos, com o objetivo de revelar as potencialidades de pesquisa dos documentos escritos.

O códice AL 014, catalogado no IEB/USP, foi descrito neste estudo, em sua materialidade, não só para fazer-se conhecer detalhadamente aos leitores, como 
também para contribuir com o delineamento de sua trajetória e autenticidade. Da mesma forma, as propriedades materiais do manuscrito, como o suporte, a tinta, o instrumento de escrita, as anotações tardias, os carimbos e até mesmo os danos causados pelos insetos contam sobre a sua história de produção, circulação e transmissão ao longo do tempo.

A escrita, cuja presença física no suporte material pode ser analisada sob aspectos da leitura, do traçado e das datações tópica e cronológica, identificando "o que", "quando", "onde" e "como" o documento foi escrito, contribui para a investigação da autenticidade do manuscrito. As análises formal e histórica da escrita fornecem, por sua vez, evidências para que se caracterize melhor "quem" escreveu o texto e "por que" o escreveu, para que se possa refletir sobre as práticas de escrita e de leitura no contexto administrativo setecentista.

Com a fixação do texto, torna-se possivel identificar a sua estrutura formal, ou seja, verifica-se que na sua criação foram seguidas as formalidades diplomáticas exigidas para essa espécie documental, análise cujos resultados definem a autenticidade e fidedignidade do documento. Além disso, a Diplomática analisa a sua forma de transmissão. No caso da carta-régia, verificamos que se trata de uma cópia autenticada, portanto, com a mesma fé notarial e força jurídica do original.

Um texto editado é um novo testemunho do manuscrito. A carta-régia recebeu uma edição semidiplomática no processador de texto Word, da Microsoft, ganhando um novo suporte, que lhe confere maior longevidade e preservação. Pudemos, pela análise da cultura material do manuscrito e do códice onde se encontra encadernado, visualizar a sua trajetória, tendo sido produzido com cuidados para durar muito tempo, circulado no seu trâmite administrativo entre Portugal e o Brasil Colônia quando foi enviado pela metrópole, em 1755, e depois entre Brasil e Portugal, quando foi copiado e encaminhado à metrópole, em 1777. Após cumprir o seu ciclo de vida nos arquivos correntes e intermediários, chegou ao Arquivo permanente pelas mãos do colecionador Alberto Lamego e entrou para a história, pronto para ser estudado pela comunidade científica.

A Bibliografia material, mais uma ciência aliada à Filologia para descrever as técnicas do livro impresso, junta-se às Humanidades digitais e às demais disciplinas que estudam o texto escrito para refletir sobre as novas posturas diante da sua digitalização. Não se pode negar os beneficios da digitalização para a democratização da consulta aos arquivos e bibliotecas. É preciso, entretanto, rever as maneiras de lidar com os direitos autorais e com a catalogação, classificação e descrição bibliográfica dos textos digitais, para garantir a sua preservação e o acesso pelos pesquisadores.

Além disso, torna-se cada vez mais importante a manutenção dos serviços das bibliotecas e arquivos para a preservação dos documentos e livros na forma como os conhecemos, ou seja, na sua materialidade.

\section{MATERIAL CULTURE AS A PHILOLOGICAL DISCIPLINE: FROM MANUSCRIPT TO ELECTRONIC TEXT}

Abstract: To reflect on material culture as a discipline of Philology, we will present the manuscript dated 1755, a royal letter, commenting on its trajectory, from its creation, as an administrative document, to its edition in electronic media. To this end, we use the perspective of the transdisciplinarity of Philology, which 
is intertwined with sciences such as Archiveology, Codicology, Paleography, Diplomatic, Material Bibliography and Digital humanities with the objective of bringing the written text and its questions closer to the contemporary reader.

Keywords: Material culture. Manuscript. Philology. Transdisciplinarity. Electronic edition.

\section{REFERÊNCIAS}

ACIOLI, V. L. C. A escrita no Brasil colônia: um guia para leitura de documentos manuscritos. Recife: UFPe: Massangana, 1994.

ALMADA, M. Cultura escrita e materialidade: possibilidades interdisciplinares de pesquisa. Pós, Belo Horizonte, v. 4, n. 8, p. 134-147, 2014. Disponível em: https://bit.ly/3sQ4Stv. Acesso em: 28 fev. 2021.

ARAÚJO, D. M. P. Princípios de descrição bibliográfica: bibliografia material e história do livro - contextos, permanências e rupturas. In: SEMINÁRIO INTERNACIONAL A ARTE DA BIBLIOGRAFIA, 6., 2019, Florianópolis. Anais [...]. Florianópolis: Udesc/UFSC, 2019. Disponível em: https://bit.ly/3dXpJqx. Acesso em: 28 fev. 2021

ARNS, P. E. A técnica do livro segundo São Jerônimo. São Paulo: Cosac Naify, 2007.

BELlOTTO, H. L. Como fazer análise diplomática e análise tipológica de documento de arquivo. São Paulo: Arquivo do Estado/Imprensa Oficial do Estado, 2002. Disponivel em: https://www.arqsp.org.br/arquivos/oficinas_colecao_ como_fazer/cf8.pdf. Acesso em: 16 fev. 2021.

BEllotTO, H. L. Arquivos permanentes: tratamento documental. São Paulo: Editora FGV, 2006.

BOUZA, F. Corre, manuscrito. Madrid: Marcial Pons, Ediciones de História S/A, 2002.

CAMBRAIA, C. N. Introdução à crítica textual. São Paulo: Martins Fontes, 2005.

CASTRO, I. Livro de José de Arimateia. 1984. Dissertação (Doutorado) - Universidade de Lisboa, Lisboa, 1984.

CHARTIER, R. Do códice ao monitor: a trajetória do escrito. Estudos Avançados, São Paulo, v. 8, n. 21, p. 185-199, ago. 1994. DOI 10.1590/S0103-40141994000 200012. Disponivel em: https://bit.ly/3edO8bF. Acesso em: 28 fev. 2021.

COULMAS, F. The Blackwell encyclopedia of writing systems. Oxford: Blackwell, 1999.

DIAS, E. N. A interessante estrutura e organização dos livros manuscritos. Linguagens: Estudos e Pesquisas, Catalão, v. 10-11, 2007.

FACHIN, P. R. M.; OLIVEIRA, L. C. T. R. de. A edição de textos genuinamente digitais e os caminhos da filologia nas humanidades digitais. Liinc em Revista, v. 15, n. 1, 2019. DOI 10.18617/liinc.v15i1.4589

FAVORETO, F. P. A orquestração do ornamento no Beatus de Facundus. 2016. Dissertação (Mestrado em História Social) - Faculdade de Filosofia, Letras e Ciências Humanas, Universidade de São Paulo, São Paulo, 2016. Disponível em: https://bit.ly/3bdr3DQ. Acesso em: 28 fev. 2021. 
LARA, S. H. Os documentos textuais e as fontes do conhecimento histórico. Anos 90, Porto Alegre, v. 15, n. 28, p. 17-39, dez. 2008. Disponivel em: https:// bit.ly/3uP5S2W. Acesso em: 28 fev. 2021. DOI 10.22456/1983-201X.7953

MAGALHÃES, J. P. Escrita e municipalismo na transição do Brasil colônia e na ideação do Brasil independente. Revista de História Regional, v. 19, n. 2, p. 298311, 2014. Disponivel em: https://bit.ly/3kC2inM. Acesso em: 28 fev. 2021.

MARQUILHAS, R. Filologia oitocentista e critica textual. In: ALVES, F. M. et al. (org.). Filologia, memória e esquecimento. Act. 20. Lisboa: Húmus, 2010. p. 355-367. Disponivel em: https://bit.ly/3882BBT. Acesso em: 28 fev. 2021.

MENESES, U. T. B. A cultura material no estudo das sociedades antigas. Revista de História, n. 115, 1983. DOI 10.11606/issn.2316-9141.v0i115p103-117.

MENESES, U. T. B. O campo do patrimônio cultural: uma revisão de premissas. In: FÓRUM NACIONAL DO PATRIMÔNIO CULTURAL - CONFERÊNCIA MAGNA, 1., 2009, Ouro Preto. Anais [...]. Ouro Preto, 2009. Disponivel em: https://bit. ly/3kDmjKN. Acesso em: 28 fev. 2021.

PETRUCCI, A. Prima lezione di paleografia. Roma: Editori Laterza, 2002.

TOLEDO NETO, S. A. Datação e localização dos tipos de escrita: informações relevantes para a crítica textual? In: LOSE, A. D.; SOUZA, A. S. de (org.). Paleografia e suas interfaces. Salvador: Memória \& Arte, 2018. Disponivel em: https://bit.ly/3rdGdP6. Acesso em: 28 fev. 2021. 